\title{
Is the rate of disappearance of echo contrast from the interventricular septum a measure of left anterior descending coronary artery stenosis?
}

\author{
F. J. Ten Cate, P. W. Serruys, H. Huang*, N. De Jong and J. Roelandt \\ Thoraxcenter, Erasmus University Rotterdam, Rotterdam, The Netherlands
}

KEY WORDS: Myocardial contrast echo, coronary artery stenosis, T50, myocardial blood flow.

Although myocardial contrast echo has been used recently in human studies, no study is available at the present time which relates contrast echo findings to the degree of coronary artery stenosis. The present study is the first attempt to determine whether a quantitative relationship exists between regional myocardial echo contrast disappearance rate ('washout') and the severity of coronary artery stenosis.

Manual injection of sonicated iopamidol (Iopamiro ${ }^{\circledR} 370$ ) into the left main coronary artery with simultaneous cross-sectional echo registration provided the myocardial echo-contrast images. From the digitized images, an echo contrast time-intensity curve was constructed for the proximal basal interventricular septum (region I) and the mid-distal portion of the interventricular septum (region II). From these curves, T50 was calculated after Fourier transformation and mono-exponential curve fitting. The percentage stenosis area $(\% A)$ of the left descending coronary artery $(L A D)$ was calculated from routine coronary arteriograms using a computer-based system. Thirty patients ( 22 men, 8 women; mean age $58 \pm 10$ years) were included in the study. Group I $(\mathrm{n}=7)$ had normal LAD, group II $(\mathrm{n}=18)$ had LAD stenosis of varying degrees. Five patients were not suitable for quantitative evaluation. A curvilinear relation was found between T50 and \%A. $\left(T 50=3.0 \times e^{0.01 \% A} ; \mathrm{r}=0 \cdot 78 ; \mathrm{P}<0.05\right)$.

Patients with asynergy had significantly longer T50 $(8 \cdot 2 \pm 2.5 \mathrm{~s})$ than did patients without asynergy $(4 \cdot 2 \pm 1 \cdot 5 \mathrm{~s})(\mathrm{P}<0 \cdot 05)$. All patients with $>75 \%$ LAD \% A had prolonged T50. T50 might be useful index for studying regional myocardial perfusion during cardiac catheterization.

\section{Introduction}

Among the various methods that have been described for measuring myocardial perfusion ${ }^{[1-4]}$, myocardial contrast cross-sectional echocardiography ${ }^{[5-9]}$ is a recent development. Its experimental and clinical applications ${ }^{[10,11]}$ have been described in which the authors have used the technique to measure the 'area at risk' or to determine the size of a perfusion defect.

Quantification of regional myocardial perfusion by this method has been measured in animals but, as yet, not in patients with coronary artery disease.

Submitted for publication on 11 September 1987 and in revised form 17 March 1988.

Address for correspondence: Folkert J. Ten Cate, M.D., Erasmus University Rotterdam, Department of Cardiovascular Research, 23rd floor, P.O. Box 1738, 3000 DR Rotterdam, The Netherlands.

*Dr Huang was a Cardiac Research fellow (World Health Organization) from Tongji Medical University, Wuhan, People's Republic of China.
Recent advances in the development of computer technology and echo contrast agents have made this present study possible by calculating the echo contrast disappearance or 'washout' rate (T50) after routine coronary arteriography. Because we do not know the clinical relevance of any such information, the present study reports our experience using this technique during cardiac catheterization. As such it is the first attempt to bring this method into clinical practice.

\section{Methods}

PATIENTS

Thirty patients (22 men, 8 women; mean age $55 \pm 12$ years) who underwent coronary arteriography for diagnostic purposes were included in the study after informed consent. The study protocol was approved by the Thoraxcenter Medical Ethical Committee. It was decided that the study should not prolong the catheterization procedure by more 
than $10 \mathrm{~min}$. Although several cross-sectional images were available, we decided to use only apical four-chamber views for quantitative analysis.

The patients were divided into two groups: Group I (7 patients) who had normal coronary arteries, and Group II comprising 23 patients who had abnormal coronary arteries. The left anterior descending coronary artery (LAD) was used for analysis by quantitative coronary arteriography (see Table 1). A quantitative relationship between the echo method and quantitative coronary arteriography could be calculated in 25 patients.

\section{Table 1 Coronary arteriography findings in Group II}

\begin{tabular}{ll}
\hline $\begin{array}{l}\text { Quantitative LAD analysis } \\
0-25 \% \text { area stenosis }\end{array}$ & 1 \\
$26-50 \%$ area stenosis & 5 \\
$51-75 \%$ area stenosis & 6 \\
$76-99 \%$ area stenosis & 6 \\
& \\
RCA findings & 3 \\
Dominant & 6 \\
Nondominant & 3 \\
Virtually occluded & 6 \\
Normal & \\
\hline & \\
\hline & The Cx findings are not described in detail. For further expla- \\
nation see text. LAD, left anterior descending coronary \\
artery; RCA, right coronary artery; Cx, circumflex branch of \\
left coronary artery numbers indicate number of patients.
\end{tabular}

\section{QUANTITATIVE CORONARY ANGIOGRAPHY}

This procedure has been described in detail previously ${ }^{[12]}$. Briefly, the analysis was carried out with the help of a computer-based coronary angiography analysis system (CAAS). The boundaries of a proximal LAD segment (before the first septal branch) were detected automatically after optical magnification and digitization of the images. Calibration of the diameter data from the vessel in absolute values $(\mathrm{mm})$ was achieved by detecting the boundaries of the contrast filled catheter and comparing the computed mean diameter in pixels with the known size in millimeters.

From the detected contours, the minimal diameter was determined by the computer and the percentage area $(\% \mathrm{~A})$ stenosis calculated, assuming circular cross-sections, as $\% \mathrm{~A}=[1-(\mathrm{minimal}$ diameter/reference diameter) $\left.{ }^{2}\right] \times 100$. $^{2}$

\section{MYOCARDIAL CONTRAST ECHOCARDIOGRAPHY}

The study was carried out immediately after coronary arteriography. The 7F Judkins catheter was left in the ostium of the main coronary artery and $4 \mathrm{ml}$ of sonicated iopamidol (Iopamiro 370) was injected at a controlled speed of $1 \mathrm{ml} \mathrm{s}^{-1}$ (dead space catheter $1.2 \mathrm{ml}$ ) under continuous registration of the echocardiographic four-chamber view using a $3.5-\mathrm{MHz}$ transducer and a Hewlett Packard AC 77020. Sonication was performed using a Heat Systems Sonicator W. 225 $5^{[13]}$.

The video-recorded images were digitized by a home-built video-scanned memory ( $256 \mathrm{Kbyte}$ ), interfaced to an Olivetti M24 computer. A region of interest with known pixel number was put on the proximal (region I) and mid-portions (region II) of the interventricular septum (Fig. 1) (resolution of images was $512 \times 512$ pixels). Only end-diastolic frames were chosen. From mean pixel intensity the computer constructed a time-intensity curve of echo contrast appearance and disappearance. Thereafter, the initial intensity was subtracted from the curves.

After Fourier transformation, T50 was calculated according to the formula $\mathrm{T} 50=\ln 2 / \mathrm{k}$ where $\mathrm{k}$ is the experimental disappearance rate ${ }^{[14]}$. T50 was always calculated for the first fast portion of the curve (Fig. 2).

\section{WALL-MOTION ABNORMALITIES}

Myocardial wall thickening ( $\%$ ) was calculated by measuring the end-diastolic (EDT) and endsystolic (EST) wall thickness and using

$$
\frac{\text { EST-EDT }}{\text { EDT }} \times 100 \%
$$

The images were also qualitatively analyzed by two observers as hypokinesia-akinesia, dyskinesia and normal.

\section{Statistical analysis}

Simple regressions were performed to find the best fit between $\% \mathrm{~A}$ and T50. Student's $t$-test was used to compare different groups. The differences between the groups were considered significant if $P<0 \cdot 05$. Values are expressed as mean $\pm \mathrm{SD}$. Interand intra-observer variations were evaluated using linear regression analysis and the standard error of the estimate was calculated.

\section{Results}

REGIONAL T50 IN GROUPS I AND II

The results are shown in Table 2. In group I, T50 


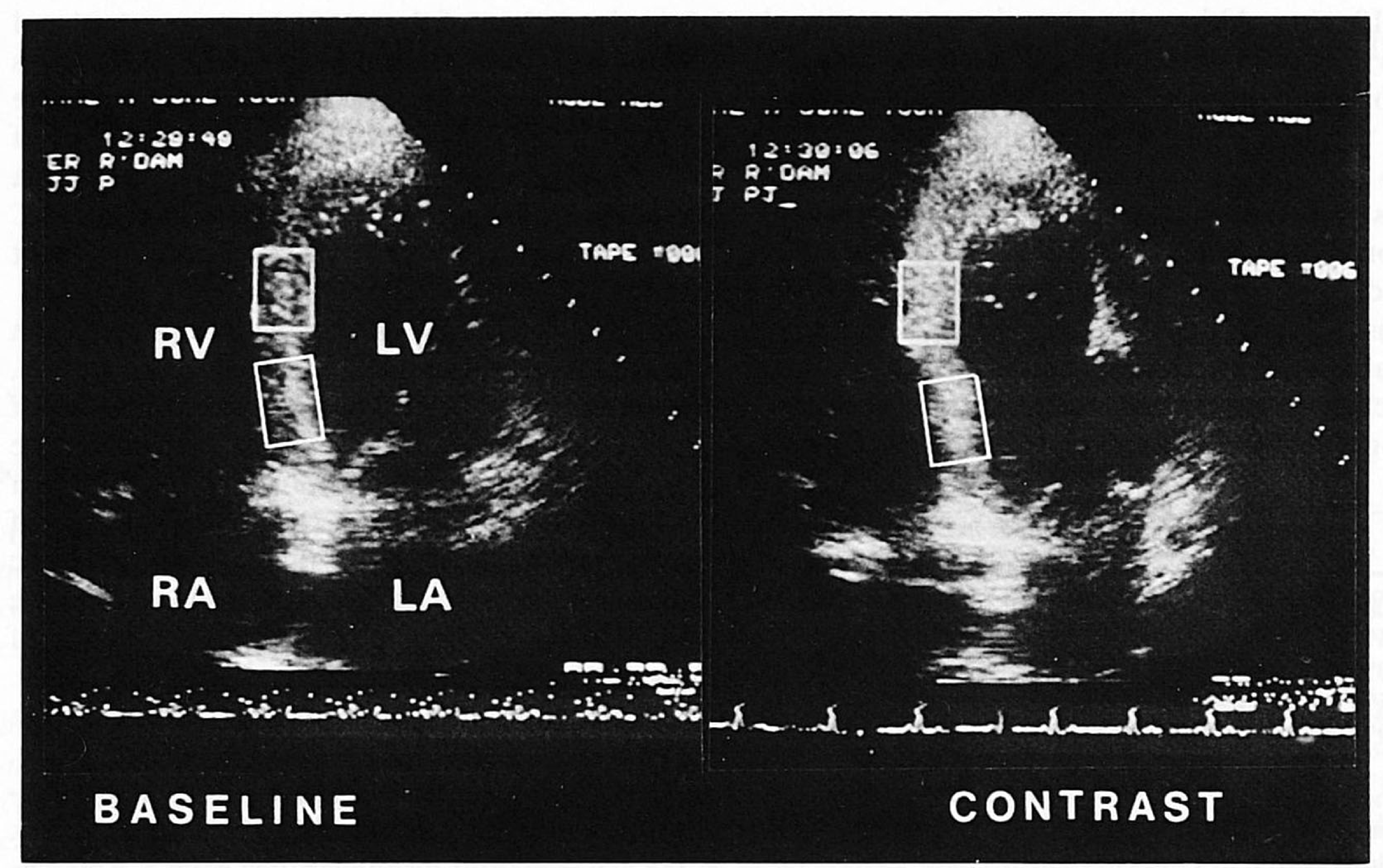

rïgure 1 Representative cross-sectional echocardiogram from four-chamber apical view. The squares indicate the regions of interest of which the video intensity is measured (Region I and II). For further explanation text.

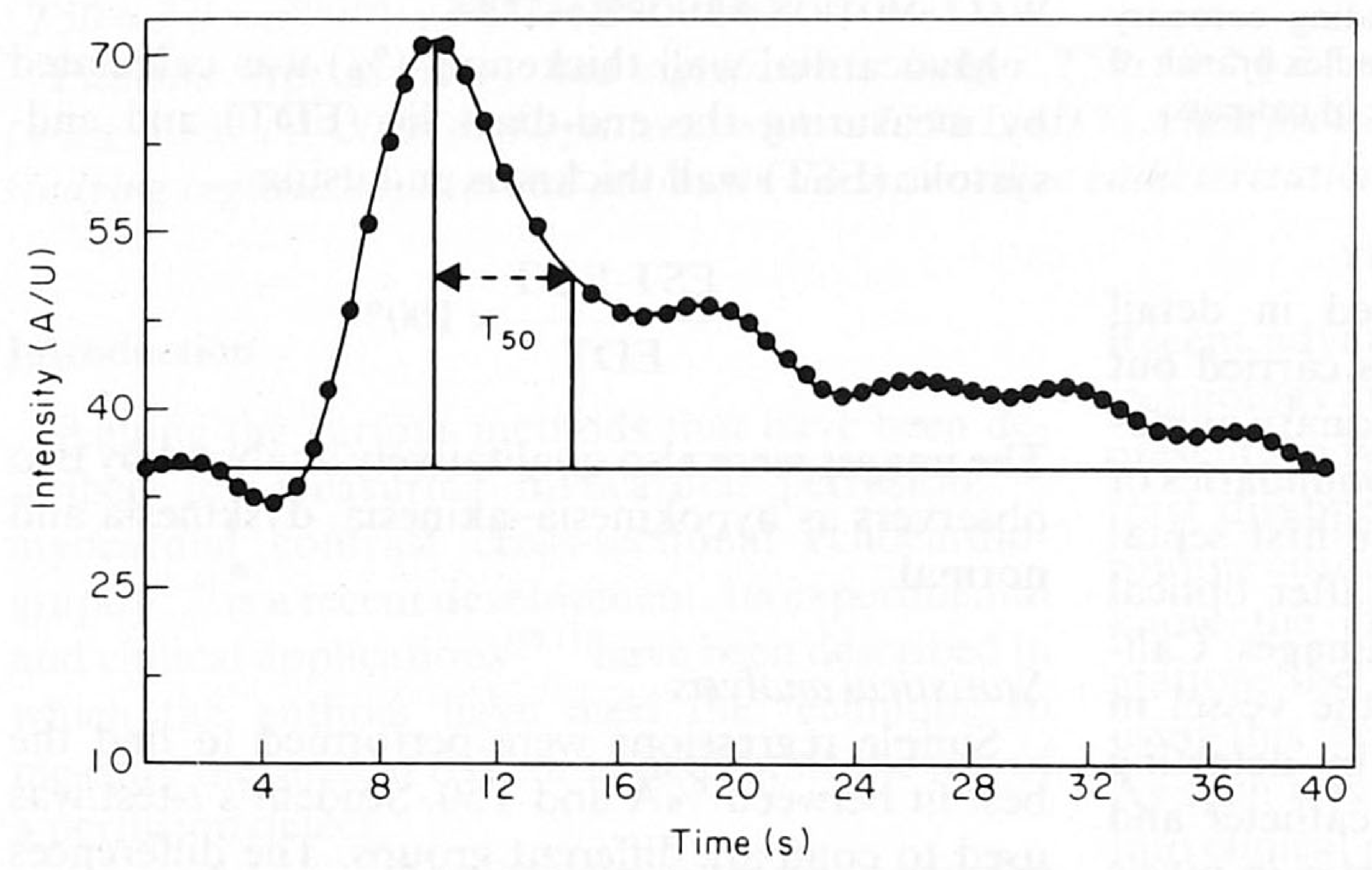

Figure 2 Diagrammatic representation of a time-intensity curve. The basic intensity is subtracted and T50 is measured as indicated. For further explanation see text.

was $4 \cdot 1 \pm 1.4 \mathrm{~s}$ in Region I and $4 \cdot 2 \pm 1.5 \mathrm{~s}$ in Region II $(P=$ NS). In Group II, patients with $<50 \%$ area stenosis had T50 values comparable to group I $(P=\mathrm{NS})$ for both Region I and II. The T50 time for significant stenosis was prolonged to $9 \cdot 5 \pm 3 \cdot 3 \mathrm{~s}$ $(P<0 \cdot 05)$ for Region I and to $9 \cdot 2 \pm 3 \cdot 7 \mathrm{~s}$ for Region
II $(P<0 \cdot 05)$. However, T50 gradually increased at $\%$ A stenosis larger than $75 \%$ (see also Fig. 3 ). The relation between $\mathrm{T} 50$ and $\% \mathrm{~A}$ stenosis was: T $50=$ $3.0 \times \mathrm{e}^{0.01 \% \mathrm{~A}}(r=0.78, P<0.05)$. These findings are comparable to the findings of Ikeda et al. ${ }^{[3]}$ using digital angiography. 
Table 2 Regional Myocardial T50

T50 (s)

\begin{tabular}{lll}
\cline { 2 - 3 } & Region I & Region II \\
\hline Group I & $4 \cdot 1 \pm 1 \cdot 4$ & $4 \cdot 2 \pm 1 \cdot 5$ \\
Group II $>50 \% \mathrm{~A}$ & $9 \cdot 5 \pm 3 \cdot 3^{*}$ & $9 \cdot 2 \pm 3 \cdot 7^{*}$ \\
\hline
\end{tabular}

${ }^{*} P<0.05$.

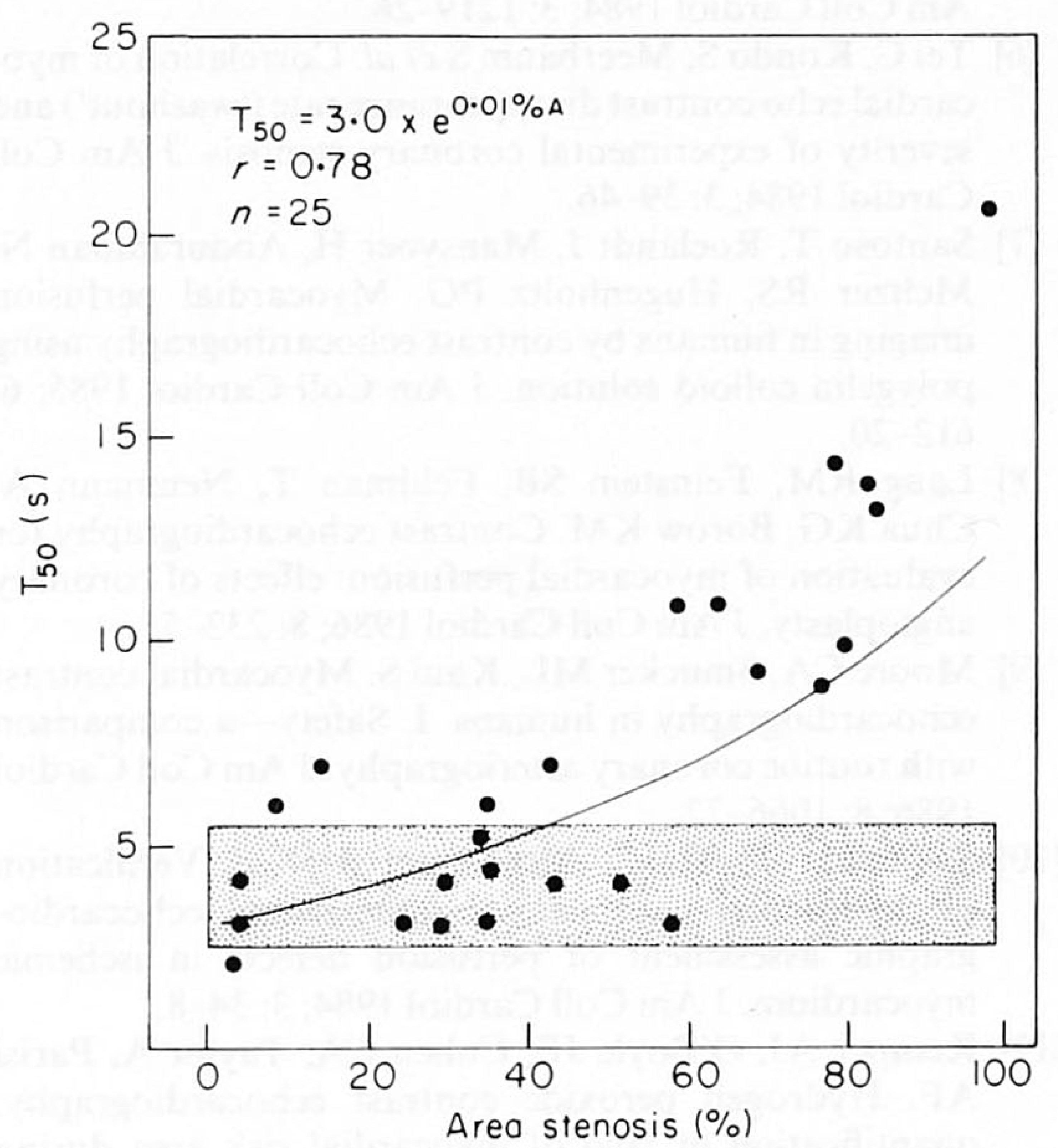

Figure 3 Relation between $\% \mathrm{~A}$ stenosis of the LAD and T50 of interventricular septum (Region I). T50 $=3.0 \times \mathrm{e}^{0.01 \% A}$ $(r=0 \cdot 78)$. The shaded area indicates the normal range of T50. For further explanation see text.

RELATION BETWEEN WALL-MOTION ABNORMALITIES AND T50

All patients with wall-motion abnormalities of inter-ventricular septum (hypokinesia/dyskinesia or akinesia) by cross-sectional echo had prolonged T50 $(8 \cdot 2 \pm 2 \cdot 5 \mathrm{~s})$ as compared to patients without wall-motion abnormalities $(4 \cdot 2 \pm 1 \cdot 5 \mathrm{~s} \quad(P<0.05)$. If wall thickening was calculated, the following relation was found:

$$
\mathrm{T} 50=\frac{1}{1+0 \cdot 03 \% \text { wall thickening }}
$$

\section{Reproducibility of T50 measurements}

Inter-observer variability for T50 showed $r=$ 0.89 with a standard error of $0.9 \mathrm{~s} \quad(P<0.05)$, whereas intra-observer variability showed $r=0.84$ with a standard error of $1.0 \mathrm{~s}(P<0.05)$.

\section{Discussion}

The present study provides a novel approach to studying myocardial perfusion using contrast echocardiography. The myocardial contrast disappearance rate (T50 or 'washout') was correlated with the severity of coronary artery stenosis $(r=0 \cdot 78$, $P<0.05$ ) by a curvilinear relationship (T50= $\left.3.0 \times \mathrm{e}^{0.01 \% \mathrm{~A}}\right)$. Although several experimental studies ${ }^{[5,6,15-17]}$ have shown that T50 is correlated with epicardial flow ${ }^{[5]}$ or severity of coronary artery stenosis ${ }^{[6]}$, the present study is the first clinical study of this sort. Furthermore, as can be seen from the calculated T50 values, the echo-contrast material used has physiologic transit times ${ }^{[5]}$ indicating that a real marker of myocardial perfusion is potentially available. Areas with wall-motion abnormalities show longer washout rates (T50) than normal contracting muscle. Moreover, T50 could be measured regionally at different places in the interventricular septum.

Furthermore, our measurements show that T50 with normal LAD and with $<50 \%$ area stenosis are similar. Therefore the measurement of T50 might indicate whether or not a stenosis on coronary arteriography influences myocardial perfusion.

Ikeda et $a l^{[3]}$ have presented similar findings using digital angiography. Thus the availability of newer echo-contrast agents with small microbubbles providing physiologic myocardial tran$\mathrm{sit}^{[8,13]}$ and the use of computerized analysis both for echocardiography ${ }^{[18]}$ and coronary arteriography provides a potentially useful index of myocardial perfusion during cardiac catheterization.

\section{LIMITATIONS OF THE STUDY AND FUTURE}

\section{IMPROVEMENTS}

A practical limitation of the present study which is present in all echo-imaging during cardiac catheterization is echo-image quality. However, newer echo equipment is foreseen where the reflected ultrasound signal is digitized directly; this avoids the need for videodensitometry. In fact, a first approach using this method has been described recently by Monaghan ${ }^{[19]}$ and is under development in our own laboratory.

The availability of a standardized contrast agent with known microbubble size and quantity is of utmost importance for a clinical echo contrast perfusion method. The first experimental results using 
this contrast agent have been reported recently ${ }^{[20]}$. Standardized injections using pump injections with known velocity of injection are now used by us. The method seems particularly useful in assessing the effects of various interventions such as angioplasty on myocardial perfusion. The present study shows that prolonged myocardial T50 always indicated severe LAD stenosis. If our results are confirmed by others and could be extended to other areas of perfusion such as posterolateral walls (circumflex area), we believe that the clinical value of this method would be increased and that more applications will be described. Although the patients for this study were only selected for the presence of a significant LAD stenosis, T50 reflects regional myocardial blood flow because the injections were performed selectively in the area of LAD perfusion. Thus intracoronary injections of echo contrast reflect not only the area of perfusion (perfusion related coronary artery) but also quantify myocardial pefusion as was shown in the present study.

\section{Conclusions}

Myocardial echo contrast washout rate (T50) shows a curvilinear relation with percentage area of coronary artery stenosis. T50 is prolonged in areas of decreased wall thickening and can be measured regionally. The proposed index might be used in the future to assess the effect of various interventions such as angioplasty.

We are grateful for the secretarial assistance of Henny Vegter. The personnel of the cardiac catheterization laboratory is thanked for their patience. Petr Widimsky, M.D., analysed many of the echo contrast images. Johannes C. Reiber, Ph.D., provided assistance in analysing the coronary arteriograms. We thank George Sutherland, M.D., for his valuable criticisms. This study is supported by Grant 85060 of the Nederlandse Hart Stichting, 's Gravenhage,. The Netherlands.

\section{References}

[1] Gould KL, Goldstein RA, Mullani NA et al. Noninvasive assessment of coronary stenoses by myocardial perfusion imaging during pharmacologic coronary vasodilation. VIII. Clinical feasibility of positron cardiac imaging without a cyclotron using generatorproduced Rubidium-82. J Am Coll Cardiol 1986; 7: $775-89$.

[2] Nichols AB, Brown C, Han J, Nickoloff EL, Esser PD. Effect of coronary stenotic lesions on regional myocardial blood flow at rest. Circulation 1986; 74: 746-57.
[3] Ikeda H, Koga $Y$, Utsu F, Toshima H. Quantitative evaluation of regional myocardial blood flow by videodensitometric analysis of digital subtraction coronary arteriography in humans. J Am Coll Cardiol 1986; 8: 809-16.

[4] Vogel R, LeFree M, Bates E et al. Application of digital techniques to selective coronary arteriography: use of myocardial contrast appearance time to measure coronary flow reserve. Am Heart J 1984; 107: 153-64.

[5] Ten Cate FJ, Drury JK, Meerbaum S et al. Myocardial contrast two-dimensional echocardiography: experimental examination at different coronary flow levels. A Am Coll Cardiol 1984; 3: 1219-26.

[6] Tei C, Kondo S, Meerbaum S et al. Correlation of myocardial echo contrast disappearance rate ('washout') and severity of experimental coronary stenosis. J Am Coll Cardiol 1984; 3: 39-46.

[7] Santoso T, Roelandt J, Mansyoer H, Abdurahman N, Meltzer RS, Hugenholtz PG. Myocardial perfusion imaging in humans by contrast echocardiography using polygelin colloid solution. J Am Coll Cardiol 1985; 6: $612-20$.

[8] Lang RM, Feinstein SB, Feldman T, Neumann A, Chua KG, Borow KM. Contrast echocardiography for evaluation of myocardial perfusion: effects of coronary angioplasty. J Am Coll Cardiol 1986; 8: 232-5.

[9] Moore CA, Smucker ML, Kaul S. Myocardial contrast echocardiography in humans. I. Safety-a comparison with routine coronary arteriography. J Am Coll Cardiol 1986; 8: 1066-72.

[10] Sakamaki T, Tei C, Meerbaum S et al. Verification of myocardial contrast two-dimensional echocardiographic assessment of perfusion defects in ischemic myocardium. J Am Coll Cardiol 1984; 3: 34-8.

[11] Kemper AJ, O’Boyle JE, Cohen CA, Taylor A, Parisi AF. Hydrogen peroxide contrast echocardiography: quantification in vivo of myocardial risk area during coronary occlusion and of the necrotic area remaining after myocardial reperfusion. Circulation 1984; 70: $309-17$.

[12] Reiber JHC, Serruys PW, Kooijman CJ et al. Assessment of short-, medium-, and long-term variations in arterial dimensions from computer-assisted quantitation of coronary cineangiograms. Circulation 1985; 71: $280-8$.

[13] Feinstein SB, Ten Cate FJ, Zwehl W et al. Two dimensional contrast echocardiography. I. In vitro development and quantitative analysis of echo contrast agents. J Am Coll Cardiol 1984; 3: 14-20.

[14] Papoulis A. The Fourier integral and its applications. New York: McGraw-Hill, 1962: 1-34.

[15] Maurer G, Ong K, Haendchen R et al. Myocardial contrast two-dimensional echocardiography: comparison of contrast disappearance rates in normal and underperfused myocardium. Circulation 1984; 69: 418-29.

[16] Kemper AJ, Force T, Kloner R et al. Contrast echocardiographic estimation of regional myocardial blood flow after acute coronary occlusion. Circulation 1985; 72: 1115-24.

[17] Kondo S, Tei C, Meerbaum S, Corday E, Shah PM. Hyperemic response of intracoronary contrast agents during two-dimensional echocardiographic delineation of regional myocadium. J Am Coll Cardiol 1984; 4: $149-56$. 
[18] Ong K, Maurer G, Feinstein S, Zwehl W, Meerbaum S, Corday E. Computer methods for myocardial contrast two-dimensional echocardiography. J Am Coll Cardiol 1984; 3: 1212-8.

[19] Monaghan MJ, Quigley PJ, Metcalfe JM, Thomas SD, Jennit DE. Digital subtraction contrast echocardio- graphy: a new method for the evaluation of regional myocardial perfusion. Br Heart J 1988; 59: 12-20.

[20] Dick CD, Feinstein SB, Peterson E, Stark VJ, Ryam JN, Harper PV. Biodistribution of a transpulmonary echocardiographic contrast agent. Circulation 1987; 76(Suppl. II): IV-506. 